\title{
Value conflict among adolescents in relation to modernization
}

\author{
Savita Rathour and Tejpreet K. Kang
}

Received: 25.07.2020; Revised: 07.10.2020; Accepted: 21.10 .2020

See end of the paper for authors' affiliations Savita Rathour Department of Human Development, Punjab Agricultural University, Ludhiana (Punjab) India Email : savitarathour@ yahoo.com)
ABSTRACT : Different choices and actions are rooted in values which define what an individual considers good or beneficial to his well being. The necessity of making choices cause conflict and it is very natural, it arises when two or more incompatible goals are active at the same time. Modern era is characterized by technological development and economic prosperity on one hand and cut-throat competition and value erosion on the other. This paradoxical situation affects adolescent's ability to decide between sets of values which in turns may or may not associated with value conflict. The present study is an attempt to investigate the relationship between adolescents' attitude towards modernization and extent of value conflict among them. This study also reveals the contribution of modernization as a determinant in value conflict in terms of gender and locale. For the present study a sample of 400 adolescents was taken from six government and private colleges situated in urban and rural areas of Ludhiana district. Value conflict scale by Bhardwaj and Comprehensive Modernization Inventory by Ahluwalia and Kalia were used to collect the data. Results revealed that attitude of adolescents was significantly negatively correlated with value conflict among rural and urban girls and boys. On the basis of regression analysis there was a significant positive contribution of different dimensions of modernization on positive value assumption among adolescents. Adolescents with positive attitude towards different aspects of modernization had greater inclination towards positive values.

GEY WORDS: Value conflict, Modernization, Rural, Urban, Adolescents

- HOW TO CITE THIS PAPER : Rathour, Savita and Kang, Tejpreet K. (2020). Value conflict among adolescents in relation to modernization. Asian J. Home Sci., 15 (2) : 192-198, DOI: 10.15740/HAS/AJHS/ 15.2/192-198. Copyright@ 2020: Hind Agri-Horticultural Society. 